\title{
Metformin Hydrochloride Encapsulation by Alginate Strontium Hydrogel for Cartilage Regeneration by Reliving Cellular Senescence
}

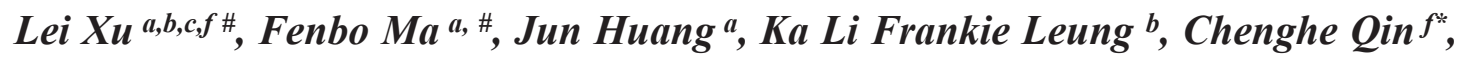
William Weijia Lu ${ }^{b^{*}}$, X. Edward Guo ${ }^{c^{*}}$, Bin Tang ${ }^{a, d, e^{*}}$

a Department of Biomedical Engineering, Southern University of Science and Technology, Shenzhen, Guangdong, P. R. China

b Department of Orthopeadics and Traumatology, LKS Faculty of Medicine, the University of Hong Kong, HK SAR, P. R. China

${ }^{\mathrm{c}}$ Bone Bioengineering Laboratory, Department of Biomedical Engineering, Columbia University, New York, NY, USA

${ }^{\mathrm{d}}$ Guangdong Provincial Key Laboratory of Cell Microenvironment and Disease Research

e Shenzhen Key Laboratory of Cell Microenvironment

${ }^{\mathrm{f}}$ Department of Orthopeadics and Traumatology, Guangdong Second Provincial General Hospital, Guangzhou, Guang Dong, P. R. China

\#These authors contributed equally to this work.

*Corresponding authors: 
Professor Bin Tang, Email: orthoxl@163.com Tel: $\underline{\text { 86-0755-88018998 }}$

Professor X. Edward Guo, Email: ed.guo@columbia.edu Tel: $\underline{\text { 01-212-854 } 6196}$

Professor W. William Lu, Email: wwlu@hku.hk Tel: $\underline{852-97381980}$

Professor Chenghe Qin, Email: doctorqin@163.com Tel:6-020-8916 8086

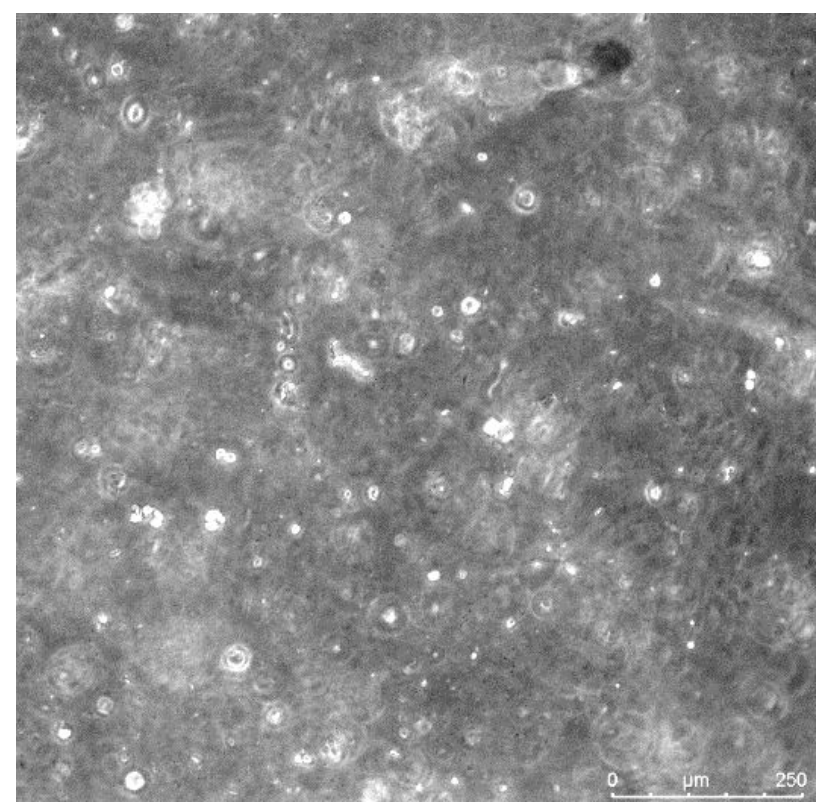

Figure S1. Representative image of encapsulated chondrocytes in the hydrogels observed under a microscope.

Table S1. Primers' sequences used for quantitative real-time PCR.

\begin{tabular}{lll}
\hline Target & Oligonucleotide & Sequence \\
\hline$\beta$-Actin & Forward & TGACGTGGACATCCGCAAAG \\
& Reverse & CTGGAAGGTGGACAGCGAGG \\
IL-1 $\beta$ & Forward & CTCCGACCACCACTACAGCAA
\end{tabular}


Reverse

MMP-9

MMP-13

p53

p21

$\mathrm{Bcl} 2$

Aggrecan

Collagen II
Forward

Reverse

Forward

Reverse

Forward

Reverse

Forward

Reverse

Forward

Reverse

Forward

Reverse

Forward

Reverse
CAACACGCAGGACAGGTACAG

CCGGACCAAGGATACAGTTT

CAGTGAAGCGGTACATAGGG

TCTACACCTACACCGGCAAA

TTAGGGTTGGGGTCTTCATC

CAGCACATGACGGAGGTTGT

TCATCCAAATACTCCACACGC

CCTGTCACTGTCTTGTACCCT

GCGTTTGGAGTGGTAGAAATCT

TCGCCCTGTGGATGACTGA

CAGAGACAGCCAGGAGAAATCA

GAGGATGGCTTCCACCAGT

TGGGGTACCTGACAGTCTGA

CAACAACCAGATTGAGAGCA

CCATGTTGCAGAAAACCTTC 


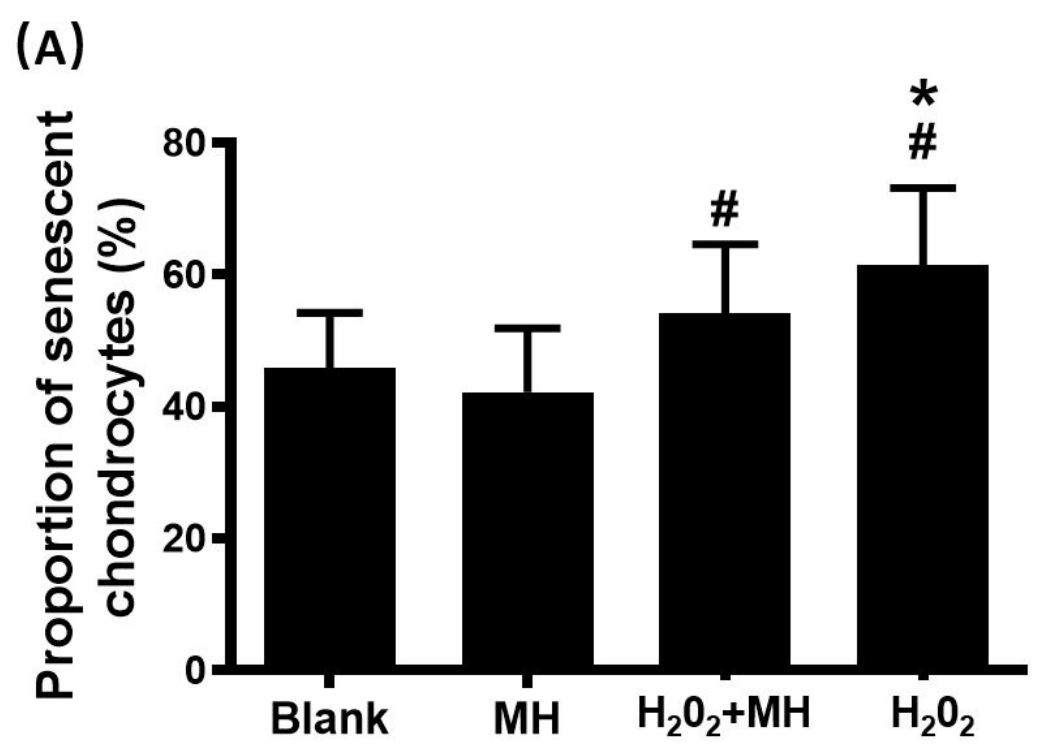

(B)

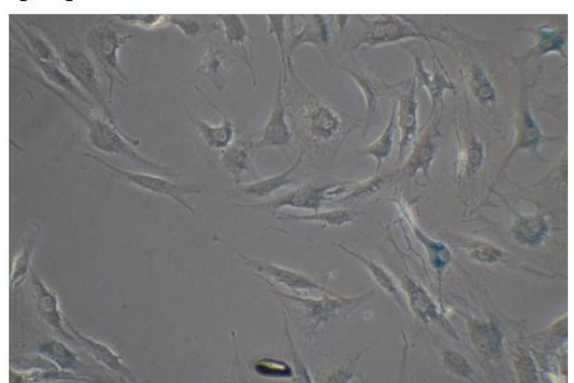

Blank

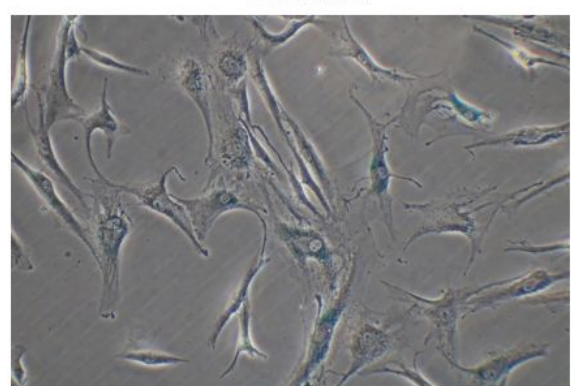

$\mathrm{H}_{2} \mathrm{O}_{2}+\mathrm{MH}$

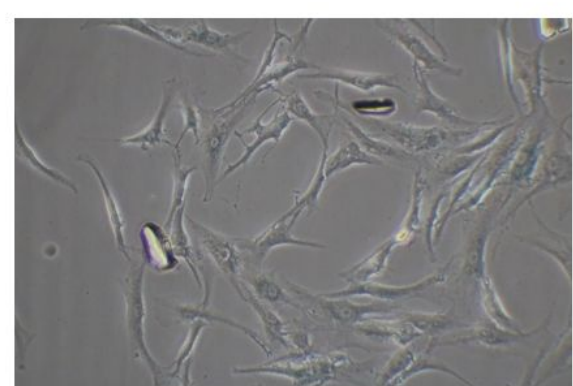

$\mathrm{MH}$

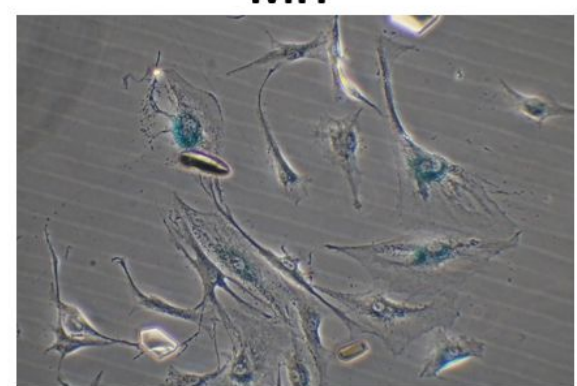

$\mathrm{H}_{2} \mathrm{O}_{2}$

Figure S2. The histogram indicating the proportions of senescent chondrocytes (A) and the representative pictures (magnification: $40 \times$ ) of different groups (B).

*indicates a significant difference compared with the blank group with $p$ value less than 0.05 . 